\title{
Organizations Management and Strategy of College Students' Sports Associations
}

\author{
Xin $\mathrm{Li}^{1, \mathrm{a}}$, Jingjing Guan ${ }^{2, \mathrm{~b}}$ \\ ${ }^{1,2}$ Qiqihar Medical University, Qiqihar, Heilongjiang, 161006 \\ aemail, ${ }^{\text {bemail }}$
}

Keywords: University Students, Physical Associations, Management and Countermeasures

\begin{abstract}
College Student Association of University Students is self-organized mass organizations, the majority of school students in the ideological and political education and the construction of campus culture and achieves an important carrier and effective way to school training objectives. Student Sports Union is an important branch of student organizations, college students has become an important part of school life, but there have been many problems. Therefore, the ability of the Student Sports Associations effective and proper scientific management, to play a greater role in the overall growth and success of college students in colleges and universities is an important topic of the current management research.
\end{abstract}

\section{Introduction}

The fundamental task of colleges and universities is to train qualified builders and successors of socialism, student organizations play an irreplaceable role in personnel training colleges and universities. The twenty-first century, to accelerate the pace of reform of higher education, college student organizations also will be booming. On the one hand, College Student Association team has grown, the number one student organizations rapidly rising, expanding, emerging new society; the second is the number of a large number of community members is also increased, community activities and the quality of the scale of activity continues to rise, by virtue of its "community spirit" in the history of sedimentation and colorful community activities, teachers and students become more and more popular, mushroomed rapid development. On the other hand, the function and role of the community college students has become increasingly prominent, not just stay in the interests of simple culture, but gradually become college students self-education, self-management, self-fashioning, an important way to self-improvement, but also an important manifestation of spiritual civilization in school ethos, style of study, young students in the cohesion and prosperity of campus culture, to carry out effective ideological and political work, extending the arm CYL work to promote student talent employment has played an important role.

As college students' organizations were an important part of the sports associations with the development of student societies and development, we have made a long-term process of development in some success, but because of its own particularity exposed many problems, such as insufficient funds venue, activity level is not high, difficult to manage members, community organizations and some internal management turmoil, some even by the community in the name of illegal activities, which gives management university presents unprecedented challenges to poor management students will have the healthy growth of the opposite effect, and even the Western bourgeoisie, hostile forces such as the use of political associations penetration tools. All of these issues are in fact revealing the contradictions of limited university resources and the growing number of community and student demand. How to resolve this contradiction requires management process we are more in-depth study of College Student Sports Union, to the adoption of effective management of the limited resources to achieve maximum effectiveness in Universities to maximize the realization of university education, training objectives, better service the majority of the students' growth. 


\section{The Definition of Student Sports Associations}

For the definition of community college students from the following elements of student organizations to summarize: the nature of community members (college students, voluntary, the same or similar interests), organizational nature (mass organizations), organizational goals (promoting physical and mental health of students). But with the development of the times, people for the development of community college students and has the functions of understanding more and more rich and profound, but also more and more attention and emphasis on student self-management societies function, this paper should be considered for the College Student Association there are more comprehensive definition: College student association refers to college students on a voluntary basis, unlimited professional grade and other conditions, by the same interests and hobbies student autonomy statute in accordance with certain activities and students form mass organizations, college students self-education, self-management, and effective form of self-service carrier in order to promote students' physical and mental development as the goal, and carry out community extracurricular activities in school leadership and support departments.

For the Student Sports Union explanation, it comes from the following several aspects: community members nature (college students, voluntary, the same or similar sports hobbies), organizational nature (mass organizations), organizational goals (physical ability to cultivate and promote the development of students' physical and mental health, enhance physical fitness of students), members are involved in motivation (to experience the sport fun, learn and improve technical skills and sports, to ease the pressure of learning, expand exchanges). In summary, for the definition of the Student Sports Union it is not very comprehensive, and therefore, the paper Student Sports Union to make such a definition: Student Sports Union refers to college students on a voluntary basis, without major, grade and other conditions restrictions, have the same interest in sports, hobbies, student self-development, construction and management, in order to promote the development of the individual as the goal, and conduct after-school sports activities groups in the school's leadership and support. .

\section{The University Student Sports Associations Operating Mode}

By sports associations responsible person in charge of the school and the community work that teacher interviews, school and sports department in charge of the Communist Youth League school, is a condominium community management effective method. On the one hand, vocational college sports associations in recent years the rapid development of broad categories, quantity, limited financial resources alone, the lack of manpower League school is difficult to specifically fine guidance and management of each community. Also school sports department has a strong guiding force, equipment, complete site, just to solve the problem of lack of resources, sports associations; on the other hand, a wide range of sports associations in high vocational colleges, it is difficult to rely on various types of Communist Youth League school community unified requirements and management. School athletic department just well versed in the characteristics of each individual sport, it is possible for different projects targeted management.

On the one hand for approving and monitoring mechanism needs to be improved, although a small number of vocational colleges have certain approval system, the students submit their applications for approval before being set up through the Communist Youth League. But in recent years Vocational Colleges continue to encourage the establishment of student organizations, most schools are generally commissioned Associations or Youth League to approve the establishment of societies, school-related departments only need to record. The establishment of a relatively simple procedure, regulatory measures in place, can not avoid trouble appear.

On the other hand the community still needs to sort out its management mechanism, the majority of students according to their interests and hobbies to choose clubs, but the basic operation of the community does not care. Time to go to the community activity, complete activity left for other community knew nothing about. Community self-promotion is not in place, if not the internal 
community and effective information through various channels to convey to the students, which is bound to affect members of the community as a whole understanding. Therefore, the establishment of conditions relaxed, backward management mechanism for the development of society inevitably lay hidden.

\section{The University Student Sports Mass Management Mechanism}

Through investigation, we found that each person is responsible for generating methods have advantages and disadvantages. School administrations dispatch or community leaders appointed after nomination by the competent authority to approve the appointment, ignoring the community "autonomy", emphasizing the development of the school community-oriented; community leaders directly appointed like "patrimonial" traditionally, community members should not be a function of democratic education a good play; internal community of democratic elections, although in line with the voices of the crowd, but for small, micro society is concerned, when the general community, only three members of the two main umbrella in maintaining community survival, meaning that democratic elections would cease to exist.

The decline in the community process, with the loss of its members is inevitable. Multiplayer co-sponsored the establishment of the community in the management decision-making places primarily responsible decisions based consultation. At the same time this decision-making process is the association stationary manner most likely development is a manifestation of the healthy functioning of society. For all members of the community co-decision on this way, theoretically feasible, in concrete work, members of the association itself arbitrary strength and greatly reduced its operability. If we see a great attraction and a lack of community hard and fast rules, all members together to participate in a management decision can only be empty talk. If it can manage the required decision-making, which is huge community member fluidity characteristics contradict. Therefore, in the community management decision-making process, we must vigorously promote democracy, and fully mobilize the enthusiasm of community members to participate in community activities, while also closely Phases of community self-development, self-realization community management, self-improvement and self-development.

Featured activities will generally get a double effect. On the one hand, there is no corporate culture club activity. Carry out cultural community building and community activities go hand in hand, not to any corporate culture building community-based activities are in vain; on the other hand, the construction of cultural activities in the community-based, community activities is the development of an effective carrier bearing culture, no Construction of community activities talk about corporate culture is meaningless. Therefore, corporate culture construction process, whether in what way, the success of every sports activity is fundamental.

Cultural shift in society between prosperity a loss for both sides of the process. Shift means a loss of the community members resulting in the decline of its corporate culture and similar corporate culture flourished. Prosperity means a loss for both the overall environmental impact on society. A community can affect the success of the activities carried out to the surrounding community health activities.

\section{The University Student Sports Mass Development Strategy}

A good society must be pregnant with unique advanced corporate culture and organizational culture is a decision factor in life, community life tied to its culture. Fudan University "Unlimited Volleyball Association" in order to perfect interpretation of the concept of Infinity movement without limits, without limitation movement, adhering to the corporate culture "IECE" community work ethic, and has its own flag, emblem, journal, will shirt, website, characteristic culture slogan, community purpose and mission, ensuring the spiritual strength of the organization, promotes the formation of collective cohesion, giving vitality to the organization.

Corporate culture and is the source of the core competitiveness of the community, Fudan University, "Unlimited Volleyball Association" and the Shanghai University of Finance and 
Economics "thunder skating club" in their respective areas of expertise have formed a unique core culture, when the core of this culture to be set extension, there must be conducive to the formation of the whole school community culture. A good cultural atmosphere, community members will have a great sense of identity, promote the sustainable development of the organization. On the one hand, "Unlimited Volleyball Association" through a number of hands-on activities to do projects to promote the building of internal culture, not only exercise the body and mind of students to meet the students' interest in hobby activities, but also promote mutual among students exchanges and cooperation, increase the students 'collective sense of honor, help students form a down to earth and pragmatic spirit; on the other hand, "Unlimited Volleyball Association", "wind and thunder skating club" and "students' Association of the fans" through activities, friendly competition, etc. methods continue exchanges and cooperation with other associations through the exchange of inter-school learning for other communities eclectic culture, combined with their actual situation, to innovative development and to further improve its own cultural characteristics, and through the exchange of community can also exercise students organizational skills, interpersonal skills, in favor of the socialization process of students.

In addition, network applications are the future trend of College Student Association. Today's society is the social network information, network play an increasing role, but many in the community to promote its route network as the most convenient way, but use less. At present, most students' sports organizations do not have their own websites, not keep up with the times, is not conducive to a better self-promotion. "Unlimited Volleyball Association" from Fudan University in 1998 to become the first to have its own forum on the BBS community in 1999 has its own home page, in the community in 2007 opened his own home space, network construction to make the school's diversity students can learn more about the community-related information, and other school and community better communication. This not only enhances the propaganda associations, expanding the influence, but also can save the propaganda funds, more importantly, allows students to use a quick way to understand community awareness, so that the community influence has been increasing, community cultural Construction of continuous improvement.

Through a wide range of social practice, so that students leave school, into the community, into the community, using the learned knowledge and skills to serve the community, to serve the public in the process, the contact with the community, understand the community, to enhance the students' ability and social practice social adaptability, and increased knowledge of students in activities to improve the quality and increase the experience, exercise capacity, accelerated the process of socialization of students.

Through the broad participation of social services, to enhance the social influence of the community, expansion of social identity, for the introduction of social funds for social support is important. Again, through the combination of social and sports organizations, sports associations can take advantage of social manpower, material resources and wit, weaknesses promote their own development and jointly build a sports and social interaction, mutual benefit, sharing of lifelong physical linkage of the bridge, Constructing new mode of College PE societies and Social Sports development.

\section{Conclusion}

The students' sports organizations are to develop into a service-oriented society and it is an important direction for future community development. Currently Student Sports Union, mostly training type exercise type, race, histrionic, communication type, etc., and service-oriented society almost no guide sports associations develop into a service club is a new attempt to community development, not only for students learn best in service activities, establish a sense of service, but also to enable students to serve the community in their own life, additional students through community service and social communication, contact, also a student to participate in social, community experience way. 


\section{Acknowledgements}

2015 Qiqihar Medical Social Science Foundation funded project Title: Development of Qiqihar Medical College Student Sports Organizations Analysis and research services supplied ID: QYSKL2015-03.

\section{References}

[1] Wang Wanzhen, Peng Guoqiang. Survey of development Collegiate Athletic Association Vocational Colleges in Jiangsu Province [J]. Journal of Changzhou Institute of Information Technology, 2012, 11 (4): 71-73.

[2] Mo Fan. University Students Sports Club and Organization Management [J]. Physical Research, 2007, 28 (3).

[3] Yang Zuo, Duan Hua, Lin Tang. Study on College Students Sports Associations and Countermeasures [J]. Hubei Sports Science, 2005,24 (4): 535-537.

[4] Zhang Lei. Reflection and Reconstruction in view of life on Current Situation of Physical Education Curriculum [J]. Physical Education, 2008, 15 (6): 75-79.

[5] Wang Yue. Student Societies: theory, management, case [M]. Beijing: Beijing Institute of Technology Press, 2007 (1): 111. 